\title{
Development of Competitive ELISA and CLEIA for Quantitative Analysis of Polymyxin B
}

\author{
Long $\mathrm{Xu}^{1} \cdot$ Maksim Burkin $^{2} \cdot$ Sergei Eremin ${ }^{3} \cdot$ Alberto C. P. Dias $^{1} \cdot$ Xiaoying Zhang $^{1,4}$
}

Received: 4 November 2018 / Accepted: 13 February 2019 / Published online: 25 February 2019

(C) Springer Science+Business Media, LLC, part of Springer Nature 2019

\begin{abstract}
Polymyxin B (PMB), a member of polypeptide antibiotics, is widely used for the treatment of infection in animals such as cattle, sheep, pigs, and chickens. However, it is toxic on the kidneys and nervous system, and polymyxin resistance is increasingly reported, which leaves a serious threat to human health. Therefore, it is essential to establish rapid methods for detecting PMB with high sensitivity and specificity. In this study, an anti-PMB polyclonal antibody (pAb) was obtained by immunizing New Zealand white rabbits with PMB conjugated with glycosylated bovine serum albumin (GBSA). Indirect competitive enzymelinked immunosorbent assay (ic-ELISA) and indirect competitive chemiluminescent enzyme immunoassay (ic-CLEIA) were developed. Under the optimal conditions, inhibitory concentrations ( $\left.\mathrm{IC}_{50}\right)$ of PMB were $257.1 \mathrm{ng} / \mathrm{mL}$ (ic-ELISA) and $250.8 \mathrm{ng} /$ $\mathrm{mL}$ (ic-CLEIA); the limits of detection (LOD) were $17.4 \mathrm{ng} / \mathrm{mL}$ (ic-ELISA) and $14.5 \mathrm{ng} / \mathrm{mL}$ (ic-CLEIA), respectively. Crossreactivity of the pAb toward polymyxin $\mathrm{E}$ (PME) was $257.1 \%$, and no response was found with other antibiotics. The recovery rates in spiked meat samples were $77.4 \sim 106.1 \%$ (ic-ELISA) and $84.1 \sim 107.1 \%$ (ic-CLEIA), respectively.
\end{abstract}

Keywords Polymyxin B (PMB) · Animal-derived food · Enzyme-linked immunosorbent assay (ELISA) · Chemiluminescent enzyme immunoassay (CLEIA)

\section{Introduction}

Polymyxins (PM) are pentacationic polypeptides with a common structure: a cyclic heptapeptide, a linear tripeptide portion, and a fatty acyl (FA) tail which is linked to the Nterminus of the tripeptide part (Storm et al. 1977). They have five different agents, which are described and named as polymyxins A-E (Kadar et al. 2013). They differ from each other in their amino acid sequences and FA chains. Among these molecules, only PMB and PME are available for clinical use

Xiaoying Zhang

zhang@bio.uminho.pt; zhang.xy@nwsuaf.edu.cn

1 Centre of Molecular and Environmental Biology, Department of Biology, University of Minho, Campus de Gualtar, 4710-057 Braga, Portugal

2 Department of Immunology, I. Mechnikov Research Institute of Vaccines and Sera, Moscow, Russia 105064

3 Faculty of Chemistry, M.V. Lomonosov Moscow State University, Moscow, Russia 119991

4 College of Veterinary Medicine, Northwest Agriculture and Forestry University, PostBox 19, Xinong Rd. 22, Yangling 712100, Shaanxi Province, China
(Cai et al. 2015). They are isolated from cultures of various strains of Bacillus polymyxa and related species (Liu et al. 2017; Pendela and Adams 2004). PMB has been used for the treatment of infections caused by gram-negative bacteria, especially the Pseudomonas aeruginosa and Escherichia coli (Gales et al. 2001; Orwa et al. 2000). It is the drug of first choice in the treatment of infections of the urinary tract, eye, meninges, and bloodstream. Many countries have promulgated standards for residue limits of PME. The EU and China both set up PME residue limits of $150 \mu \mathrm{g} / \mathrm{kg}$ in the animal muscle, fat, and liver and $200 \mu \mathrm{g} / \mathrm{kg}$ in the kidney. However, there is no maximum residue limit for PMB in animal-derived foods and animal feed internationally. PMB has been known to show antiendotoxin activities, and it is reported to bind to endotoxin in vitro to suppress many of its activities (Guo et al. 2007; Ronco and Klein 2014). Owing to the emergence of multidrug-resistant (MDR) gram-negative antibiotics and the reduction of newly developed antibiotics, PMB has been increasingly used as a last-resort drug in the treatment of MDR gram-negative bacterial infections (Bergen et al. 2012a; Velkov et al. 2013).

With the increasing use of PM in humans and animals, bacterial resistance has been on the increase ( $\mathrm{Li}$ et al. 2018; 
Olaitan et al. 2014). In 2010, the European Medicines Agency warned in their report (Bergen et al. 2012b) about the increasing resistance to PME, especially in Southern European countries where PME has been frequently used in agriculture. In the husbandry industry, PMB is used as a feed additive to promote animal growth. Excessive use of PMB gives rise to a large amount of residues in animal tissues, which may transfer to humans and put humans at risk for the acquisition of antibiotic-resistant pathogens (Sitzlar et al. 2012). Therefore, there is a huge need for quantification of PMB in veterinary practices and food safety inspection.

There are many different methods used for the determination of polymyxin: chromatography methods (LC-MS/MS) have been widely used and recognized as standard laboratory methods for PMB quantification and subtype identification with high sensitivity and accuracy. $\mathrm{PMB}_{1}, \mathrm{PMB}_{2}, \mathrm{PMB}_{3}$, and isoleucine- $\mathrm{PMB}_{1}$ were separated and quantified using stepwise gradient elution of water containing $0.1 \%$ of formic acid and $0.1 \%$ of trichloroacetic acid (mobile phase A) and $90 \%$ acetonitrile with $0.1 \%$ formic acid (mobile phase B) (Hee et al. 2017). These PMBs were completely resolved in the analytical run time of $6.5 \mathrm{~min}$. Immunoassay is another approach to sensitive, rapid, and cost-effective detection of antibiotics, especially for field screening of large samples. A highly sensitive ELISA was developed for the quantification of PMB sulfate with the detection limit of $32 \mathrm{pg} / \mathrm{mL}$ (Saita et al. 1999). However, this assay was aimed only for the detection of PMB sulfate in human serum samples. Consequently, it is necessary that a sensitive, rapid, and reliable method should be developed for the determination of PMB residues in animalderived foods.

The present study aimed at developing the most commonly used quantitative immunoassays, namely, ELISA and CLEIA, for PMB residue analysis in animal-derived edible tissues.

\section{Materials and Methods}

\section{Synthesis of Polymyxin B Conjugates}

The glycosylated bovine serum albumin (GBSA) was synthesized via the carbodiimide (EDAC) method (He et al.
2015). PMB (purity 98\%, China Food and Drug Verification Research Institute, Beijing, China) was conjugated with GBSA to obtain an immunogen. For the synthesis of GBSA, $10.09 \mathrm{mg}$ of bovine serum albumin (BSA), $3.30 \mathrm{mg}$ of EDAC, and $10 \mu \mathrm{L}$ D-gluconic acid (Sigma, St. Louis, MO, USA) were dissolved in $500 \mu \mathrm{L}$ PBS, and the reaction was carried out for $16 \mathrm{~h}$ at $17^{\circ} \mathrm{C}$. Then, the mixture was dialyzed against PBS $(0.01 \mathrm{~mol} / \mathrm{L}$, $\mathrm{pH}$ 7.4) at $4{ }^{\circ} \mathrm{C}$. The artificial antigens were synthesized via the sodium periodate oxidation method (Burkin and Galvidis 2010) (Fig. 1). For the synthesis of the immunizing antigen, $0.5 \mathrm{~mL}$ of $0.1 \mathrm{M} \mathrm{NaIO}_{4}$ was added dropwise to $10 \mathrm{mg}$ GBSA, which was dissolved in $3.5 \mathrm{~mL}$ PBS, and the mixed solution was stirred for $2 \mathrm{~h}$ at room temperature. Then, the mixture was reacted with $0.5 \mathrm{~mL}$ of $1 \mathrm{M}$ glycol at RT with continuous stirring for $10 \mathrm{~min}$. When the reaction ended, the solution obtained was added to $4 \mathrm{~mL}$ of PMB PBS solution and reacted for $2 \mathrm{~h}$. The $\mathrm{pH}$ value of the reaction mixture was adjusted between 9.0 and 9.5 with $5 \% \mathrm{~K}_{2} \mathrm{CO}_{3}$ solution. After this reaction, $10 \mathrm{mg} \mathrm{NaBH} 4$ was added into the mixture and reacted for $16 \mathrm{~h}$. Finally, the obtained conjugate (PMB-GBSA) was dialyzed against four changes of PBS (0.01 M, pH 7.4) for 3 days.

UV spectra (Specord 50UV-VIS spectrophotometer, Analytik Jena AG, Germany) of PMB, GBSA, and PMB-GBSA were tested at a wavelength ranging from 190 to $400 \mathrm{~nm}$. The conjugations were confirmed again by SDS-PAGE.

Similarly, the coating antigen synthesis PMB-Gelatin (PMB-Gel) was prepared as described above.

\section{Generation of Polyclonal Antibodies}

A half milliliter of saline-containing $500 \mu \mathrm{g}$ of PMBGBSA was emulsified with $500 \mu \mathrm{L}$ of Freund's complete adjuvant and administered intradermally to female New Zealand white rabbits at sites along both sides of the spine. After the initial immunization, booster injections were given four times at biweekly intervals, using $300 \mu \mathrm{g}$ of PMB-GBSA in $500 \mu \mathrm{L}$ of Freund's incomplete adjuvant (FIA, Sigma, St. Louis, MO, USA) per rabbit per
Fig. 1 Synthetic route for the immunogen. (A) Synthesis of GBSA by EDAC; (B) $\mathrm{NaIO}_{4}$ oxidizes the hydroxyl of GBSA; (C) carbonyl coupled to PMB; (D) $\mathrm{NaBH}_{4}$ reduces doublebonded carbonic acid of conjugation

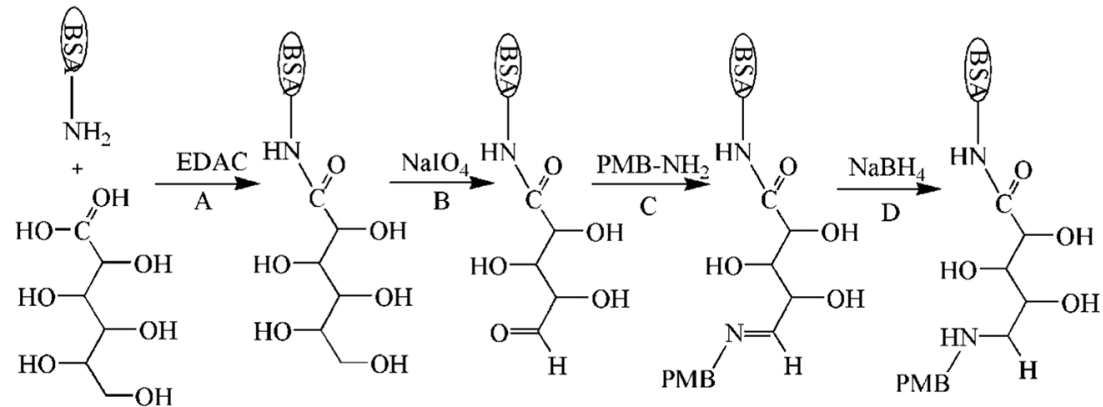


booster dose. Post-immunization blood was collected from the marginal ear vein. Blood was clot for $30 \mathrm{~min}$ and centrifuged at $5000 \mathrm{~g}$ for $5 \mathrm{~min}$, and the serum was collected. Serum aliquots were kept at $4{ }^{\circ} \mathrm{C}$ for immediate use and at $-20{ }^{\circ} \mathrm{C}$ for long-term storage. It was used as anti-PMB antiserum for ELISA and CLEIA.

\section{Indirect Competitive ELISA}

The optimal dilutions of the antibody and the coating antigen were determined by checkerboard titration at an absorption value of 1.0. According to conventional protocols (Cui et al. 2016), the ic-ELISA was carried out as follows: 96-well ELISA plates (Costar Inc., Cambridge, MA, USA) were coated with PMB-Gel $(100 \mu \mathrm{L}$ per well) in $0.1 \mathrm{M}$ sodium carbonate buffer (CBS, $\mathrm{pH} 9.6$ ) at $4{ }^{\circ} \mathrm{C}$ overnight. The plates were washed three times with PBST (0.5\% Tween-20 in PBS) and blocked with $2 \%$ BSA in PBS $\left(200 \mu \mathrm{L}\right.$ per well) at $37{ }^{\circ} \mathrm{C}$ for $2 \mathrm{~h}$. The same washing step was implemented. A series of PMB standards and samples dissolved in PBS were mixed with an equal volume of diluted serum in PBS. One hundred microliters per well of the mixture was added to the plates at $37{ }^{\circ} \mathrm{C}$ for $40 \mathrm{~min}$. After washing three times, the plates were incubated with goat anti-rabbit HRP $(100 \mu \mathrm{L}$ per well, diluted 1:8000) dissolved in PBS containing $1 \%$ BSA at $37{ }^{\circ} \mathrm{C}$ for $40 \mathrm{~min}$. The plates were washed again. Subsequently, $100 \mu \mathrm{L}$ per well of 3,3',5,5'-tetramethylbenzidine (TMB, Sigma, St. Louis, MO, USA) substrate solution was added to plates, which were then incubated at $37{ }^{\circ} \mathrm{C}$ for $10 \mathrm{~min}$. The reaction was terminated by the addition of $2 \mathrm{M}$ $\mathrm{H}_{2} \mathrm{SO}_{4}(50 \mu \mathrm{L}$ per well). The absorbance values were measured at $450 \mathrm{~nm}$.

The competition curve was established by plotting the $B / B_{0}$ values against the PMB concentrations of $5,10,25$, $50,100,250,500,1000$, and $2000 \mathrm{ng} / \mathrm{mL}$, where $B$ and $B_{0}$ represented the absorbance values of the well containing the competitor and the zero competitor concentrations, respectively, relative to the control $\mathrm{OD}_{450}$. The concentrations of PMB in the samples were quantified using the calibration curve.

\section{Cross-reactivity Assay}

Structural analogs and commonly used antibiotics such as PME, kanamycin, gentamicin, enrofloxacin, sulfadimethoxine, and chloramphenicol (Solarbio Science \& Technology Co., Ltd., Beijing, China) were studied for cross-reactivity to determine the specificity of the antibodies. Cross-reactivity (CR \%) was quantitated as follows: $\mathrm{CR} \%=\left(\mathrm{IC}_{50}\right.$ for $\mathrm{PMB} / \mathrm{IC}_{50}$ for analogs $) \times 100 \%$.

\section{Indirect Competitive CLEIA}

The optimal concentrations of PMB-Gel and anti-PMB antibody were selected using ELISA by checkerboard titration. The indirect competitive CLEIA was described as follows: $100 \mu \mathrm{L} /$ well of PMB-Gel in CBS ( $\mathrm{pH}$ 9.6) was coated on the 96-well polystyrene microtiter plates and incubated at $4{ }^{\circ} \mathrm{C}$ overnight. On the following day, the plate was washed three times using PBST and blocked by adding $200 \mu \mathrm{L}$ of PBS containing $2 \%$ BSA at $37^{\circ} \mathrm{C}$ for $2 \mathrm{~h}$. After a further washing step, $50 \mu \mathrm{L}$ of diluted pAb and $50 \mu \mathrm{L}$ of PMB standard solution were added to each well and incubated at $37{ }^{\circ} \mathrm{C}$ for 40 -min incubation. PMB standard solution was prepared by diluting with PBS at a series of concentrations $(5,10,25,50,100,250,500,1000$, and $2000 \mathrm{ng} / \mathrm{mL}$ ). After three washes with PBST, $100 \mu \mathrm{L} /$ well of goat anti-mouse IgG-HRP was added and incubated at $37{ }^{\circ} \mathrm{C}$ for $40 \mathrm{~min}$. Finally, $100 \mu \mathrm{L}$ of substrate solution prepared freshly was added into each well and incubated for $5 \mathrm{~min}$ in the dark. Then, chemiluminescence intensity was monitored on Synergy H1 (BioTek, VT, USA). The standard curve was evaluated by plotting the chemiluminescence intensity against the logarithm of each concentration and was fitted to a logistic equation using the Origin 8.0 program (OriginLab, Hampton, USA).

\section{HPLC Analysis}

The method was performed as the report described with some modification (Chepyala et al. 2015; Wan et al. 2006). The liquid chromatographic system (Agilent 1260, USA) for PMB sulfate was equipped with an LC pump delivering the mobile phase $\left(V_{\mathrm{ACN}}: V_{\mathrm{H} 2 \mathrm{O}}=90: 10\right)$ at a flow rate of $0.8 \mathrm{~mL} / \mathrm{min}$ and with an automatic injector with a loop of $60 \mu \mathrm{L}$. The stationary phase was packed in a stainless steel column $(100 \times 4.6 \mathrm{~mm}$, id $3.5 \mu \mathrm{m})$. The column temperature was maintained at $25^{\circ} \mathrm{C}$. An integrator was connected to the diode array detector (DAD) to record the signals at $220 \mathrm{~nm}$. A series of different concentrations of PMB were prepared in PBS. The calibration curve was generated via linear regression, and the linear range of PMB was calculated using the peak area ratio of PMB to the external standard (PMB).

\section{Spiked Sample Preparations and Analysis}

To verify the developed methods, the chicken, pork, and beef samples were purchased from the local market in Yangling, Shaanxi Province, China. The samples were extracted in reference to a previous report (Yu et al. 2017); briefly, each sample (1-g wet mass) was homogenized and spiked with PMB standards at different concentrations $(100,200$, and $500 \mathrm{ng} / \mathrm{g})$. Four milliliters of $0.1 \%$ formic 
acid and $2 \mathrm{~mL}$ of methanol were mixed with the tissue sample. The mixture was sonicated for $30 \mathrm{~min}$ at $60{ }^{\circ} \mathrm{C}$, and the suspension was centrifuged (Eppendorf 5804R instrument, Eppendorf, Hamburg, Germany) at $4000 \mathrm{~g}$ for $15 \mathrm{~min}$ at $4{ }^{\circ} \mathrm{C}$. The supernatants were transferred to a solid-phase extraction column and washed with $10 \mathrm{~mL}$ $\mathrm{H}_{2} \mathrm{O}$. The analyte was eluted from the column by $3 \mathrm{~mL}$ methanol and then dried under nitrogen. At last, dried samples were re-dissolved in $1 \mathrm{~mL}$ PBS and tested using the developed ELISA and CLEIA. The recovery rates were calculated on the basis of the standard curve constructed by ic-ELISA and ic-CLEIA.

\section{Results}

\section{Characterization of the Antigen}

Three absorbance curves (GBSA, PMB, and PMB-GBSA) were observed after the UV screening from 190 to $400 \mathrm{~nm}$. PMB did not have an absorption peak over $230 \mathrm{~nm}$. PMB and GBSA showed a similar characteristic absorption peak at $220 \mathrm{~nm}$. For this reason, reducing PAGE was performed to further confirm the conjugation of PMB-GBSA (Fig. 2). PMB-GBSA showed larger molecular weight.

\section{Optimization of PMB-Gel and Antiserum Work Concentrations}

The antibody working titer was determined by the checkerboard method (Fig. 3). The $\mathrm{OD}_{450}$ value 1.0 indicated that the best concentrations of the antiserum and

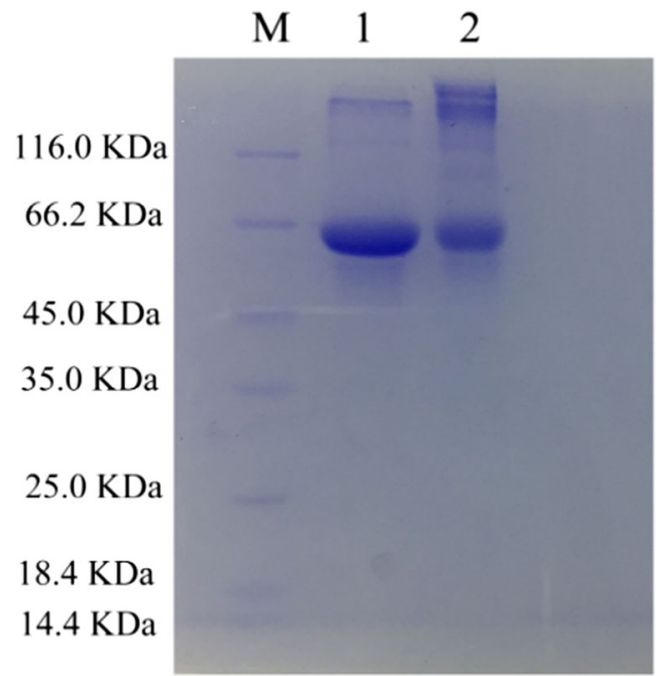

Fig. 2 Reduced PAGE analysis on GBSA (lane 1) and PMB-GBSA conjugate (lane 2)

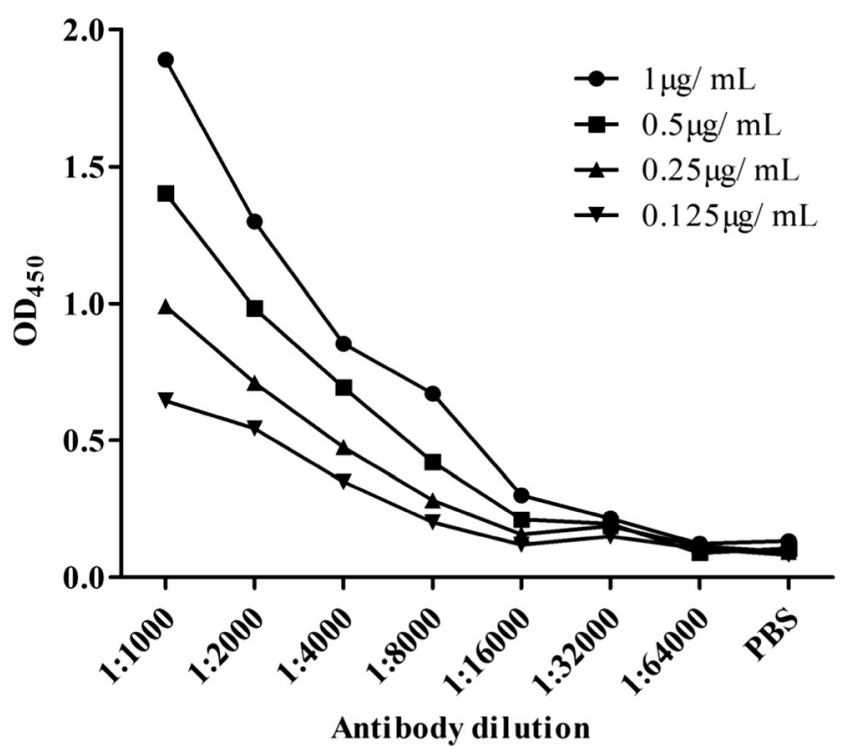

Fig. 3 Checkerboard curve of antigen-antibody of PMB. Different symbols represent increasing amount of the coated antigen

the coated PMB-Gel were fixed on 1:3000 and $1 \mu \mathrm{g} /$ $\mathrm{mL}$, respectively.

\section{Competitive ELISA}

The sensitivity of ELISA was determined under optimal conditions. In the representative competitive inhibition curve for PMB (Fig. 4), the regression curve equation of the anti-PMB pAb was $Y=-0.340 X+1.322\left(R^{2}=0.984, n=3\right)$, with the $\mathrm{IC}_{50}$ value of $257.1 \mathrm{ng} / \mathrm{mL}$ and the limit of detection $\left(\mathrm{IC}_{10}\right.$ value) of $17.4 \mathrm{ng} / \mathrm{mL}$. The $\mathrm{IC}_{50}$ value demonstrated that the antibody could be used for $\mathrm{PMB}$ detection with a linear range from 25 to $2000 \mathrm{ng} / \mathrm{mL}$.

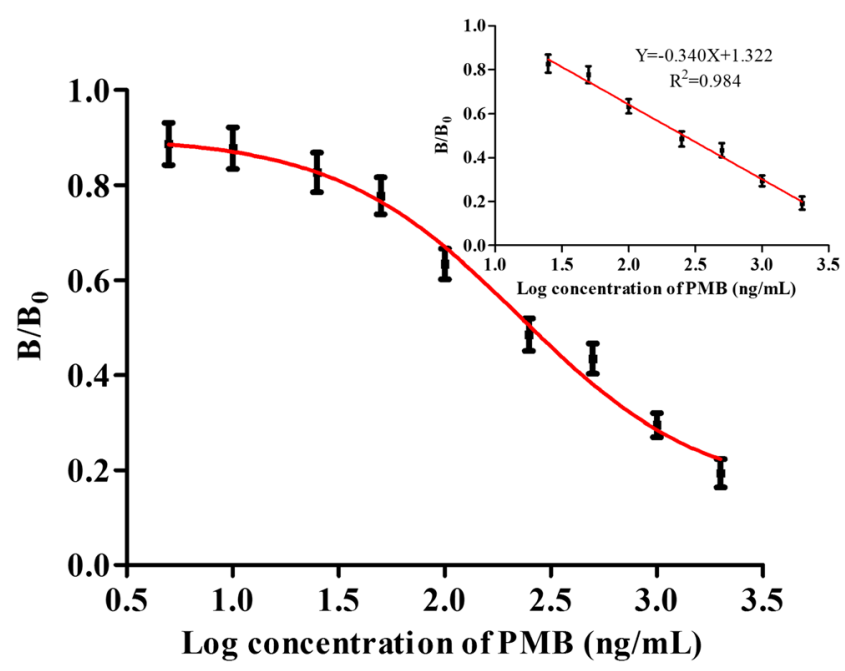

Fig. 4 Standard curve of the competitive ELISA for PMB 


\section{Cross-reactivity and Sensitivity}

The structural analogs and other antibiotics, including PME, kanamycin, sulfadimethoxine, enrofloxacin, gentamicin, and chloramphenicol, were used to evaluate the specificity of the antibody obtained. The data showed that the pAb exhibited high cross-reactivity for PME, where the cross-reactivity was $257.1 \%$ (Table 1). It was found that the pAb did not recognize the other five commonly used in veterinary antibiotics.

\section{Development of Competitive CLEIA}

The sensitivity of CLEIA was determined under the same conditions as ELISA. The representative competitive inhibition curve (Fig. 5) revealed the regression curve equation of

Table 1 Cross-reactivity of anti-PMB IgG with other antibiotics

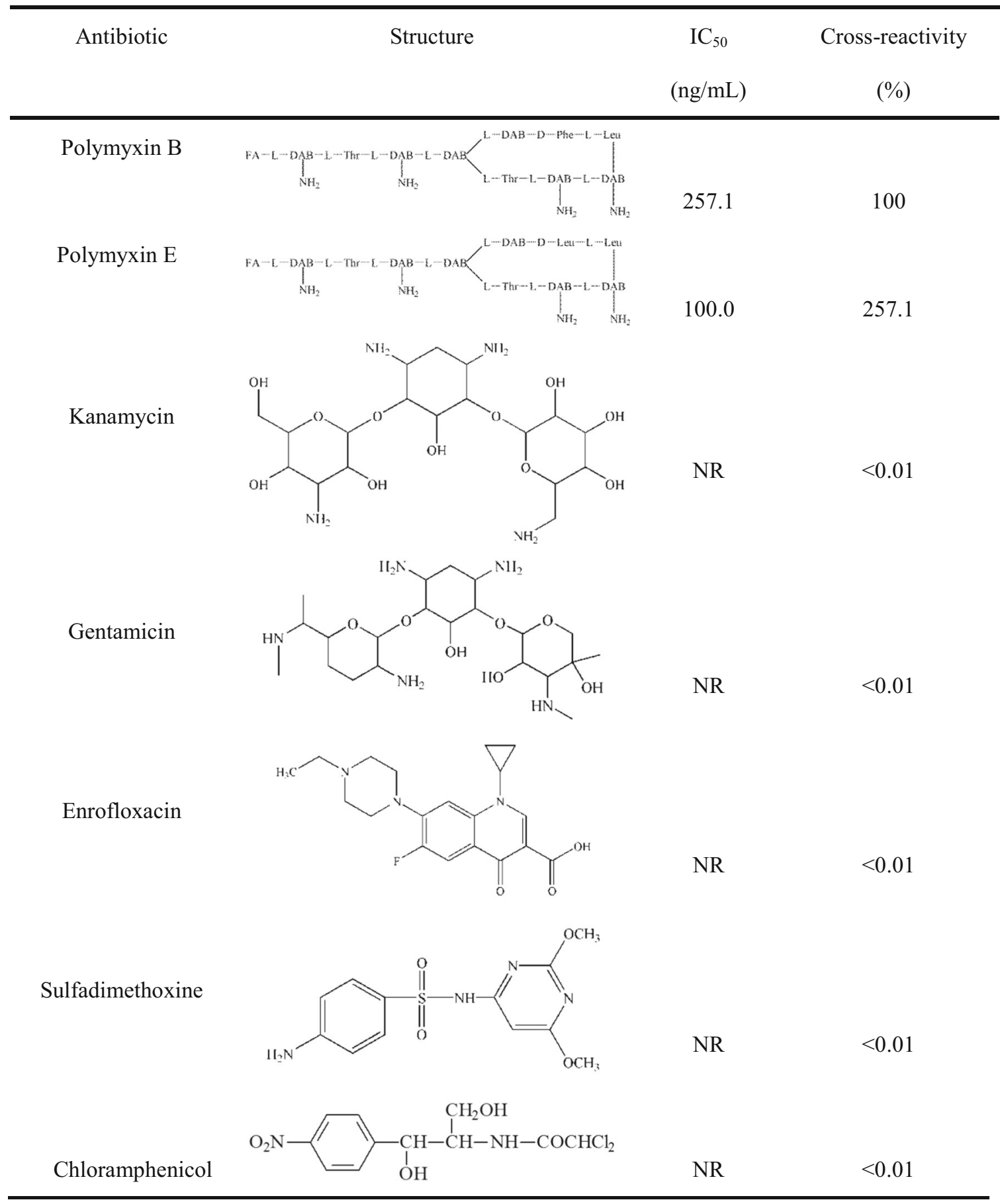




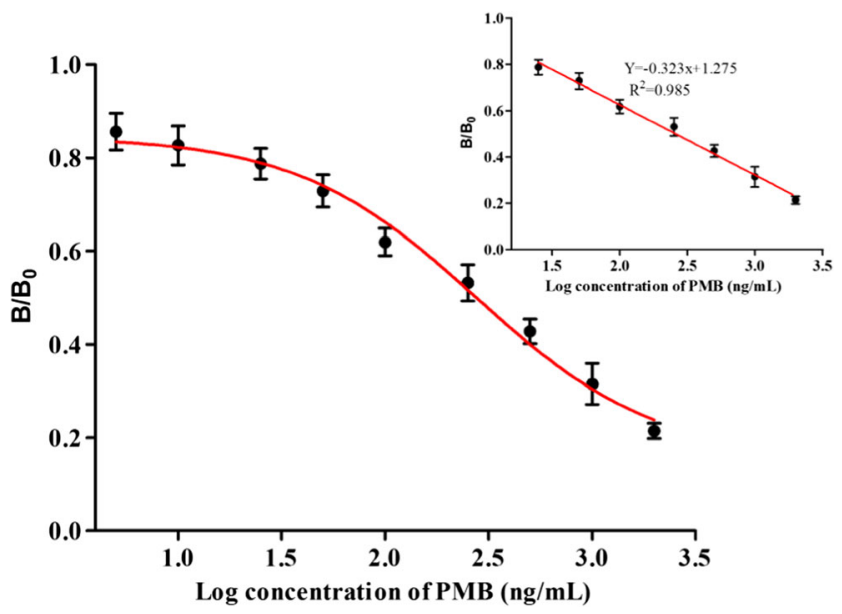

Fig. 5 Standard curve of the competitive CLEIA for PMB

$Y=-0.323 X+1.275\left(R^{2}=0.985, n=3\right)$ with the $\mathrm{IC}_{50}$ value of $250.8 \mathrm{ng} / \mathrm{mL}$ and the limit of detection $\left(\mathrm{IC}_{10}\right)$ value of $14.5 \mathrm{ng} / \mathrm{mL}$. The linear range was 25 2000 ng/mL.

\section{PMB Sulfate Analysis in HPLC}

A reversed-phase HPLC was developed for PMB determination by analyzing its major metabolite, PMB sulfate. The retention time of PMB was $0.772 \mathrm{~min}$. The regression curve equation was $Y=4.572 X-63.683\left(R^{2}=0.996, n=3\right)$. The linearity ranged from 5.0 to $500.0 \mu \mathrm{g} / \mathrm{mL}$. The LOQ, where the signal-to-noise ratio equaled 10 , was $5 \mu \mathrm{g} / \mathrm{mL}$. The LOD, where the signal-to-noise ratio equaled 3 , was $2 \mu \mathrm{g} / \mathrm{mL}$.

\section{Precision and Recovery in the Sample Test}

ELISA and CLEIA are broadly used as tools of qualitative determination. To evaluate the accuracy and precision of the developed test system in matrices, the spiked chicken, pork, and beef samples containing different concentrations of PMB (100, 200, and $500 \mathrm{ng} / \mathrm{g}$, respectively) were detected using the proposed ic-ELISA and ic-CLEIA, respectively, and both methods showed high recoveries (Table 2) and low coefficients of variation (Table 2).

\section{Discussion}

PMB and PME are commonly used to control and treat animal disease as well as promote fast and more efficient growth of livestock. Improper use of them leads to the development of antibiotic-resistant bacteria and puts animals and humans at risk for the acquisition of antimicrobial drug-resistant pathogens. PME residue determination in animal-derived food products or animal feed is already reported. Still, there is little research about PMB residue in these. A rapid and semi-quantitative nanoparticle (AuNP)-based immunochromatographic test (ICT) strip for PMB residues has been established (Li et al. 2018). Nevertheless, for quantitative detection of PMB, high specificity of the anti-PMB antibody was generated from rabbits immunized with PMB-GBSA in this study. A high crossreactivity of the $\mathrm{pAb}$ with $\mathrm{PME}$ may be attributable to their very similar molecular structure. The difference between PMB and PME is the sixth amino acid: PMB has a D-phenylalanine in its

Table 2 Recovery rates of PMB from fresh chicken, pork, and beef samples $(n=4)$

\begin{tabular}{|c|c|c|c|c|c|c|c|}
\hline \multirow[t]{2}{*}{ Sample } & \multicolumn{4}{|l|}{ ELISA } & \multicolumn{3}{|l|}{ CLEIA } \\
\hline & $\begin{array}{l}\text { Spiked } \\
(\mathrm{ng} / \mathrm{g})\end{array}$ & $\begin{array}{l}\text { Measured } \\
\text { (ng/g) }\end{array}$ & $\begin{array}{l}\text { Recovery } \\
(\%)\end{array}$ & $\begin{array}{l}\text { RSD } \\
(\%)\end{array}$ & $\begin{array}{l}\text { Measured } \\
\text { (ng/g) }\end{array}$ & $\begin{array}{l}\text { Recovery } \\
(\%)\end{array}$ & $\begin{array}{l}\text { RSD } \\
(\%)\end{array}$ \\
\hline \multirow[t]{4}{*}{ Chicken } & 0 & $<$ LOD & - & - & $<$ LOD & - & - \\
\hline & 100 & 77.4 & 77.4 & 4.8 & 84.1 & 84.1 & 8.4 \\
\hline & 200 & 175.5 & 87.8 & 6.3 & 184.3 & 92.2 & 9.0 \\
\hline & 500 & 451.5 & 90.3 & 9.7 & 429.5 & 85.9 & 4. 0 \\
\hline \multirow[t]{4}{*}{ Pork } & 0 & $<$ LOD & - & - & $<$ LOD & - & - \\
\hline & 100 & 84.1 & 84.1 & 7.0 & 84.8 & 84.8 & 12.1 \\
\hline & 200 & 212.1 & 106.1 & 7.2 & 214.2 & 107.1 & 9.3 \\
\hline & 500 & 429.6 & 85.9 & 8.4 & 448.1 & 89.6 & 8.7 \\
\hline \multirow[t]{4}{*}{ Beef } & 0 & $<$ LOD & - & - & $<$ LOD & - & - \\
\hline & 100 & 81.5 & 81.5 & 7.3 & 88.8 & 88.8 & 7.0 \\
\hline & 200 & 189.6 & 94.8 & 4.6 & 202.5 & 101.3 & 5.0 \\
\hline & 500 & 519.9 & 104.0 & 7.7 & 427.3 & 85.5 & 9.2 \\
\hline
\end{tabular}

$R S D$ relative standard deviation

No HPLC results listed, because of its low sensitivity 
cyclic portion, whereas in PME, there is a D-leucine in the same position (Landman et al. 2008; Vaara 2010). The pAb could be used for preliminary screening of PME and quantitative analysis of PMB. During sample preparation, high protein content in meat products occurs with PMB through hydrophobic interactions and hydrogen bonds, which could interfere with the determination of PMB using the developed assay. Hence, organic solvent was picked to precipitate protein and extract PMB during the pretreatment process of samples, which achieved good extraction effect and reduced the matrix interference.

As an alternative to instrumental analytical methods, ELISA and CLEIA have been considered as promising choices for large sample screening in the detection of antibiotic residues. As a fundamental and classical immunoassay, the ELISA has been applied widely with the advantages of simplicity, specificity, and low cost. Nevertheless, because the enhanced chemiluminescence reaction offers the possibility of increasing the sensitivity of CLEIA compared with conventional immunoassay detections, the CLEIA has gained more attention in recent years ( $\mathrm{Lu}$ et al. 2011; Yu et al. 2014). Besides, the light intensity of CLEIA can remain stable in 5 min after substrate addition, thus providing rapid detection of the analytical signal. The features of ic-ELISA and ic-CLEIA employed for the detection of PMB have been compared. The ic-ELISA and icCLEIA possess the same wide detection range $(25 \sim 2000 \mathrm{ng} / \mathrm{mL})$. The sensibility of ic-ELISA is lower than that of ic-CLEIA. Furthermore, the two developed assays showed higher sensitivity than HPLC with DAD.

\section{Conclusion}

A polyclonal antibody against PMB was raised by immunizing New Zealand white rabbits with PMB-GBSA. The LOD of ic-ELISA and ic-CLEIA were $17.4 \mathrm{ng} / \mathrm{mL}$ and $14.5 \mathrm{ng} / \mathrm{mL}$, respectively. They were sensitive for quantitative analysis of PMB and the large sample screening of PME in meat samples. The two methods demonstrated their potential as alternatives to the commonly used chromatography methods.

Funding Information This work was supported by the Key Program for International S\&T Cooperation Project of Shaanxi Province (2017KWZD-10), the strategic program UID/BIA/04050/2013 (POCI-01-0145FEDER-007569) funded by national funds through the FCT I. P., the Ministério da Ciência, Tecnologia e Ensino Superior (MCTES), the ERDF through the COMPETE2020 - Programa Operacional Competitividade e Internacionalização (POCI), and the Ministry of Education and Science of the Russian Federation, unique project identifier RFMEFI60417X0198.

\section{Compliance with Ethical Standards}

Conflict of Interest Long Xu declares that he has no conflict of interest. Maksim Burkin declares that he has no conflict of interest. Sergei Eremin declares that he has no conflict of interest. Alberto C. P. Dias declares that he has no conflict of interest. Xiaoying Zhang declares that he has no conflict of interest.

Ethical Approval All procedures performed in studies involving animals were in accordance with the ethical standards of the institution or practice at which the studies were conducted.

Informed Consent Informed consent was obtained from all individual participants included in the study (in case humans are involved).

Publisher's Note Springer Nature remains neutral with regard to jurisdictional claims in published maps and institutional affiliations.

\section{References}

Bergen PJ, Landersdorfer CB, Lee HJ, Li J, Nation RL (2012a) Old' antibiotics for emerging multidrug-resistant bacteria. Curr Opin Infect Dis 25:626-633

Bergen PJ, Landersdorfer CB, Zhang J, Zhao M, Lee HJ, Nation RL, Li J (2012b) Pharmacokinetics and pharmacodynamics of 'old' polymyxins: what is new? Diagn Microbiol Infec Dis 74:213-223

Burkin MA, Galvidis IA (2010) Development of a competitive indirect ELISA for the determination of lincomycin in milk, eggs, and honey. J Agric Food Chem 58:9893-9898

Cai Y, Lee W, Kwa AL (2015) Polymyxin B versus colistin: an update. Expert Rev Anti Infect Ther 13:419-427

Chepyala D, Tsai IL, Sun HY, Lin SW, Kuo CH (2015) Development and validation of a high-performance liquid chromatographyfluorescence detection method for the accurate quantification of colistin in human plasma. J Chromatogr B 980:48-54

Cui L, He J, Hao R, Zhang X, Du E, Li X (2016) Preparation of a chicken $\mathrm{scFv}$ to analyze gentamicin residue in animal derived food products. Anal Chem 88:4092

Gales AC, Reis AO, Jones RN (2001) Contemporary assessment of antimicrobial susceptibility testing methods for polymyxin B and colistin: review of available interpretative criteria and quality control guidelines. J Clin Microbiol 39:183-190

Guo YB, Chen LP, Cao HW, Wang N, Zheng J, Xiao GX (2007) Polymyxin B antagonizing biological activity of lipopolysaccharide. Chin J Traumatol 10:180-183

He J, Hu J, Thirumalai D, Schade R, Du E, Zhang X (2015) Development of indirect competitive ELISA using egg yolk-derived immunoglobulin $(\operatorname{IgY})$ for the detection of gentamicin residues. J Environ Sci Health B 51:8-13

Hee KH, Yee K, Leaw J, Ong JL, Lee LS (2017) Development and validation of liquid chromatography tandem mass spectrometry method quantitative determination of polymyxin B1, polymyxin B2, polymyxin B3 and isoleucine-polymyxin B1 in human plasma and its application in clinical studies. J Pharm Biomed Anal 140:91-97

Kadar B, Kocsis B, Nagy K, Szabo D (2013) The renaissance of polymyxins. Curr Med Chem 20:3759-3773

Landman D, Georgescu C, Martin DA, Quale J (2008) Polymyxins revisited. Clin Microbiol Rev 21:449-465

Li Y, Liu L, Song S, Kuang H, Xu C (2018) A rapid and semi-quantitative gold nanoparticles based strip sensor for polymyxin B sulfate residues. Nanomaterials 8:144

Liu T, Gao L, Zhao J, Cao Y, Tang Y, Miao P (2017) A polymyxin Bsilver nanoparticle colloidal system and the application of lipopolysaccharide analysis. Analyst 143:1053-1058. https://doi.org/10. 1039/C7AN01788J 
Lu J, Xu Y, Chu JS, Xie L (2011) Chemiluminescence enzyme immunoassay for the determination of zearalenone in corn. Food Ferment Ind 37:160-165

Olaitan AO, Morand S, Rolain JM (2014) Mechanisms of polymyxin resistance: acquired and intrinsic resistance in bacteria. Front Microbiol 5:643

Orwa JA, Van GA, Roets E, Hoogmartens J (2000) Liquid chromatography of polymyxin B sulphate. J Chromatogr A 870:237-243

Pendela M, Adams EJ (2004) Development of a liquid chromatographic method for ear drops containing neomycin sulphate, polymyxin B sulphate and dexamethasone sodium phosphate. J Pharm Biomed Anal 36:751-757

Ronco C, Klein DJ (2014) Polymyxin B hemoperfusion: a mechanistic perspective. Crit Care 18:309

Saita T, Yoshida M, Nakashima M, Matsunaga H, Fujito H, Mori M (1999) A highly sensitive ELISA for the quantification of polymyxin B sulfate in human serum. Biol Pharm Bull 22:1257-1261

Sitzlar B, Vajravelu RK, Jury L, Donskey CJ, Jump RL (2012) Environmental decontamination with ultraviolet radiation to prevent recurrent Clostridium difficile infection in 2 roommates in a longterm care facility. Infect Control Hosp Epidemiol 33:534-536
Storm DR, And KSR, Swanson PE (1977) Polymyxin and related peptide antibiotics. Annu Rev Biochem 46:723-763

Vaara M (2010) Polymyxins and their novel derivatives. Curr Opin Microbiol 13:574-581

Velkov T, Roberts KD, Nation RL, Thompson PE, Li J (2013) Pharmacology of polymyxins: new insights into an 'old' class of antibiotics. Future Microbiol 8:711-724

Wan EC, Ho C, Sin DW, Wong YC (2006) Detection of residual bacitracin A, colistin A, and colistin B in milk and animal tissues by liquid chromatography tandem mass spectrometry. Anal Bioanal Chem 385:181-188

Yu F, Yu S, Yu L, Li Y, Wu Y, Zhang H, Qu L, Harrington PB (2014) Determination of residual enrofloxacin in food samples by a sensitive method of chemiluminescence enzyme immunoassay. Food Chem 149:71-75

Yu S, Yang B, Yan L, Dai Q (2017) Sensitive detection of $\alpha$-onotoxin GI in human plasma using a solid-phase extraction column and LCMS/MS. Toxins 9:235 